Inhibition of Mycobacterium tuberculosis, Mycobacterium bovis and Mycobacterium avium by Novel Dideoxy Nucleosides

Dinesh Rai ${ }^{1}$, Monika Johar ${ }^{1}$, Naveen C. Srivastav ${ }^{1}$, Tracey Manning ${ }^{1}$, B. Agrawal ${ }^{2}$, Dennis Y. Kunimoto $^{3}$ and Rakesh Kumar ${ }^{1 *}$

\title{
Microanalytical Data
}

\begin{tabular}{|c|c|c|c|c|c|c|c|}
\hline \multirow[t]{2}{*}{ no } & \multirow[t]{2}{*}{ Empirical Formula } & \multicolumn{3}{|c|}{ Calcd. } & \multicolumn{3}{|c|}{ Found } \\
\hline & & $\mathrm{C}$ & $\mathrm{H}$ & $\mathrm{N}$ & $\mathrm{C}$ & $\mathrm{H}$ & $\mathrm{N}$ \\
\hline 2 & $\mathrm{C}_{9} \mathrm{H}_{11} \mathrm{IN}_{2} \mathrm{O}_{4}$ & 31.95 & 3.25 & 8.28 & 32.05 & 3.50 & 8.70 \\
\hline 3 & $\mathrm{C}_{14} \mathrm{H}_{18} \mathrm{~N}_{2} \mathrm{O}_{4}$ & 60.43 & 6.47 & 10.07 & 60.10 & 6.24 & 9.80 \\
\hline 4 & $\mathrm{C}_{19} \mathrm{H}_{28} \mathrm{~N}_{2} \mathrm{O}_{4}$ & 65.51 & 8.04 & 8.04 & 65.76 & 8.34 & 8.37 \\
\hline 5 & $\mathrm{C}_{21} \mathrm{H}_{32} \mathrm{~N}_{2} \mathrm{O}_{4}$ & 67.02 & 8.51 & 7.44 & 67.40 & 8.81 & 7.11 \\
\hline 6 & $\mathrm{C}_{22} \mathrm{H}_{34} \mathrm{~N}_{2} \mathrm{O}_{4}$ & 67.69 & 8.71 & 7.17 & 67.95 & 8.41 & 7.00 \\
\hline 7 & $\mathrm{C}_{23} \mathrm{H}_{36} \mathrm{~N}_{2} \mathrm{O}_{4}$ & 68.31 & 8.91 & 6.93 & 68.00 & 8.70 & 7.10 \\
\hline 8 & $\mathrm{C}_{17} \mathrm{H}_{16} \mathrm{~N}_{2} \mathrm{O}_{4}$ & 65.38 & 5.12 & 8.97 & 65.70 & 5.40 & 8.64 \\
\hline 15 & $\mathrm{C}_{11} \mathrm{H}_{14} \mathrm{~N}_{2} \mathrm{O}_{5}$ & 51.96 & 5.51 & 11.02 & 52.33 & 5.71 & 11.32 \\
\hline 16 & $\mathrm{C}_{11} \mathrm{H}_{13} \mathrm{ClN}_{2} \mathrm{O}_{5}$ & 45.75 & 4.50 & 9.70 & 45.40 & 4.75 & 9.96 \\
\hline 18 & $\mathrm{C}_{11} \mathrm{H}_{13} \mathrm{ClN}_{2} \mathrm{O}_{4} \mathrm{~S}$ & 43.35 & 4.27 & 9.19 & 43.13 & 4.61 & 9.37 \\
\hline 19 & $\mathrm{C}_{9} \mathrm{H}_{11} \mathrm{ClN}_{2} \mathrm{O}_{3} \mathrm{~S}$ & 41.14 & 4.19 & 10.66 & 41.00 & 4.25 & 10.91 \\
\hline 22 & $\mathrm{C}_{16} \mathrm{H}_{21} \mathrm{FN}_{2} \mathrm{O}_{4}$ & 59.25 & 6.48 & 8.64 & 59.58 & 6.59 & 8.46 \\
\hline 23 & $\mathrm{C}_{19} \mathrm{H}_{27} \mathrm{FN}_{2} \mathrm{O}_{4}$ & 62.29 & 7.37 & 7.65 & 62.51 & 7.48 & 7.38 \\
\hline 24 & $\mathrm{C}_{21} \mathrm{H}_{31} \mathrm{FN}_{2} \mathrm{O}_{4}$ & 63.95 & 7.86 & 7.10 & 64.31 & 8.18 & 7.37 \\
\hline 25 & $\mathrm{C}_{22} \mathrm{H}_{33} \mathrm{FN}_{2} \mathrm{O}_{4}$ & 64.70 & 8.08 & 6.86 & 64.48 & 8.30 & 6.46 \\
\hline
\end{tabular}




\begin{tabular}{llllllll}
\hline 26 & $\mathrm{C}_{23} \mathrm{H}_{35} \mathrm{FN}_{2} \mathrm{O}_{4}$ & 65.40 & 8.29 & 6.63 & 65.77 & 8.20 & 6.93 \\
27 & $\mathrm{C}_{20} \mathrm{H}_{21} \mathrm{FN}_{2} \mathrm{O}_{4}$ & 64.51 & 5.64 & 7.52 & 64.38 & 5.43 & 7.26 \\
\hline
\end{tabular}

